\title{
The use of technology in a Technical English classroom
}

\author{
Antonio D. Juan Rubio - Isabel M. Garcia Conesa \\ Universidad Internacional de La Rioja - Centro Universitario de la Defensa San Javier \\ Spain
}

\begin{abstract}
Teachers are experiencing important changes, whether they have already turned into reality or not, in the daily classroom work in most of our school centres due to the progressive establishment and incorporation of ICTS. These changes allow the development of new didactic materials of an electronic nature which use varied and different standings for their carrying into practice. These new standings of information generate a huge communicative innovation provoking as such new settings of collaborative learning process. With the scope of getting used to the needs of the present society of knowledge, the Spanish education system in all its areas of knowledge, specifically that of Technical English, and by extension the whole scholar network, must develop new ways of integrating the new information and communication technologies in its daily teaching practice. It is also advisable, at the same time, a change of mentality so as to face the traditional roles assumed by both teachers and students in these teaching practices. This is mainly reflected in the proper channels of communication as well as in the design of new methodologies and teaching practices. The aim of this article is to set the role of the modern FL teacher in a Technical English classroom when facing the massive use of ICTs in the teaching-learning process as well as all the resources at their disposal for their didactic exploitation. We will focus our attention in those specific cases of FL teachers and the wide range of resources which they can make use of. Henceforth, we will deepen in this article the need to get used to the new methodological tendencies and the possibilities that the use of ICTs allows us in our daily classroom practice. Therefore, we will enumerate some practical methodological orientations so as to be able to face them in a serious, determined, organized, and structured way.
\end{abstract}

Key words: didactic innovation - ICTs - flexible methodology - multimedia resources - Technical English classroom

\section{INTRODUCTION}

The Information and Communication Technologies (ICT) are unquestionable and they are part of the technological culture that surrounds us and with which to live together. They expand our physical and mental abilities and our possibilities of social development. According to Franziska Lys "it is not the technology that makes teaching successful but the care and thought given to the pedagogical integration of these technologies and the dynamics and opportunities that result from it" [1].

In our modern society, we are currently experiencing a sort of technological revolution that is apparently approaching too fast. So, it seems obvious that we cannot, and should not, neglect its importance since we are increasingly being demanded a more reflexive and conscious answer towards it. The present society is characterized by the increasing use of the information and communication technologies (ICTs) demanding to its citizens a series of personal, social, and professional competences in order to face the imposed changes in the fields of science and economy.
On behalf of this changing world, we are encountering an educative system which places its teaching staff on the edge since they are considered the axis of the change. Therefore, it is our duty not to let our educative centres be the last places to incorporate the new technological discoveries. Henceforth, the teaching force is getting into the treatment of ICTs step by step so as to foment the development of an intercultural and relevant teaching-learning process. Our centres have moved into a multicultural context with the aim of deepening into an intercultural setting which favours and demands the plain integration of ICTs as key learning tools.

As a result, the role of teachers has experienced big changes in the last years. Nowadays, they are not only supposed to teach, but also to help students "learn how to learn". Information is now out there and everyone can access it. To be able to deal with this revolution, to be up-to-date, teachers need to do a continuous professional development. Research never ends.

In the $21^{\text {st }}$ century, some of the tasks that educators have to accomplish are the following: understand the different learning styles; design and organize classes; set goals and accomplish them; motivate students and encourage

Corresponding Author: Antonio D. Juan Rubio, Universidad Internacional de La Rioja - Centro Universitario de la Defensa San Javier, Spain. Email: danirubio71@ @otmail.com 
participation; develop a student-based learning; understand diversity and individual needs; help students use different resources; encourage self-learning and self-evaluation; encourage students' positive attitudes (values, etc.); research inside and outside the classroom. It is also important to bear in mind that it is a common and general belief that learning to teach is a lifelong experience. Teachers are therefore supposed to experience in the classroom to be able to develop new didactic strategies and new ways of using materials and resources.

More and more often, teachers are asked to develop a research profile and to understand the relationship between the theory of L2 acquisition and the design of language materials and sessions. A critical analysis of all the knowledge and data is a very important process. Researchers in the teaching of L2 for specific purposes can use different techniques in order to develop this research profile. For example, we can mention the following techniques: classroom activities; journals; questionnaires; experimentation; case studies; new technologies.

\section{IMPACT OF ICT ON T-L PROCESS}

Changing, following the rhythm of continuous scientific advances and in a framework of economic and cultural globalization, they contribute to the rapid obsolescence of knowledge and the emergence of new values, causing continuous transformations in our economic, social and cultural structures, and influencing almost all aspects of our life. Its great impact in all areas of our life makes it increasingly difficult for us to act efficiently regardless of them.

Of all the elements that make up ICT, without a doubt, the most powerful and revolutionary is the Internet, which opens the doors to a new era, the Internet Age, in which the current information society is located. Internet provides us with a third world in which we can do almost everything we do in the real world and also allows us to develop new activities, many of them enriching for our personality and way of life. And now people can divide the time of their lives by interacting in three worlds: the physical world, constituted by atoms, governed by the laws of space, in which there are distances between things and people; the intrapersonal world of the imagination and the cyberspace, of virtual nature, constituted by bits, without distances.

The ICTs, result of scientific development, in turn influence their evolution, contributing to socioeconomic development and modifying the current value system. Although, as Sáez Vacas [2] says, "technology changes rapidly up to the way we live, but instead our own conceptions of the world are modified with laziness" ( $p$. $6)$.
There is evidence from research that ICT can help pupils to learn and teachers to teach more effectively. However, there is not a simple message of such evidence that ICT will make a difference simply by being used. Findings suggest that although ICT can improve learning there are a number of issues that need to be considered if such technology is going to make a difference. Some caution is therefore called for at this board level of where and how ICT might have an impact. There has been extensive research into computerassisted instruction (CAI) and computer-based learning (CBL). One study, Fletcher-Flynn and Gravatt, [3] into the effectiveness of CAI limited the studies it examined to those that took place between 1987 and 1992 and identified almost 400 reports of research that met these criteria. The impact of the use of computers was then combined statistically to identify the overall impact. In this meta-analysis the mean effect size was relatively small for the five years in question but increased for more recent studies analysed.

This kind of improvement would move an 'average' class of pupils from $50^{\text {th }}$ to $40^{\text {th }}$ in list of 100 classes ranked in order of attainment. This suggests two things: first, it is possible that the impact of computers may be increasing; second, ICT only produces relatively small improvement. Other forms of educational interventions, such as peer tutoring, reciprocal teaching and homework, for example, all produce greater average impact.

In a study of the effect of different types of study skills interventions the average effect would move a class from $50^{\text {th }}$ to the top 30 . A study of the effect of thinking skills or metacognitive approaches [4] indicates the average impact would move a class from $50^{\text {th }}$ into the top 20 .

A study by the British Educational Technology Association (BECTA, 2000) found no link between levels of resources for ICT and either reading or mathematics grades at Key Stage 1 in 1999. At Key Stage 2 there was a significant, but very weak, association between ICT resources and pupil attainment. This indicated that ICT curriculum researching was at least $99.5 \%$ independent of pupil performance at Key Stage 2.

In the USA, information about computer use from a longitudinal study was analysed [5]. This study also found a very small link between computer use in the curriculum in school and improvement in pupils' test scores, though again the link was very weak which indicates that at this general level computer use makes very little difference to pupils' achievement.

A similar weak link between high computer use and pupil attainment was reported in a preliminary survey for a Teacher Training Agency study in England [6] though the authors did not interpret this as a causal link, but rather as that more effective teachers tended to use 
more innovative approaches, or tended to use the resources that they had more effectively. If this interpretation is accepted it suggests that it is more important to think about how computers are used in schools.

This same study also reported dramatic impact on pupil attainment in its 16 development projects in schools. The average gain on standardized tests was 2.8 months progress per month of the project in mathematics and 5.1 months progress per month in literacy. The report states, however, that these gains do not prove that ICT will raise attainment, but rather that "teachers can raise levels of pupils attainment when they use ICT to support their teaching in literacy and numeracy".

In these projects the use of ICT was planned to have an impact on particular areas of pupils' learning using research evidence from literacy and mathematics as well as the effective use of ICT. The development work involved working closely with the class teachers over an intensive period using a range of different equipment and software. These projects did not use control groups, but the consistent and significant increase in the attainment of pupils in mathematics and English suggests that where ICT is targeted at specific areas of learning, with a clear rationale for its use from a broad research base, it can have a positive effect.

\section{INNOVATIONS IN TECHNICAL ENGLISH}

When we talk about innovation in the teaching of foreign languages, we are not saying that we have to reject all the resources which were used before the application of ICTs in education. We need to use both the previous methodology (blackboard and chalk or marker, books, pens, etc.), and also the new technologies: computers, internet, digital blackboards, etc.

When students first get into a classroom and see that there are computers, their reaction is: "Are those computers for us? Are we learning computing?" Behind these questions there is expectation and motivation. And, in the end, it is the students who demand using these new elements in the classroom.

Using ICTs in the foreign language classroom is a resource that: motivates students; compliments the teaching process; stimulates discussions and writing; helps share stories among students. We can use/make students use the new technologies in the classroom in different ways: by using commercially developed language programs or activities on the web; by assigning specific project works: make the students search for information; by encouraging students to communicate with other students (Facebook, etc.).

Like all the teaching resources we can make use of in the FL classroom, the ICTs have both advantages and disadvantages.
- Advantages: among the benefits of using ICTs we can find:

- repetition of activities

- individual and collaborative work

o motivation

- learn from mistakes

$\circ \quad$ acquisition of IT skills

$\circ$ interactivity

- multimedia

○ authenticity

$\circ$ fun

- Disadvantages: there are also some drawbacks of using ICTs in the classroom

○ IT skills are a prerequisite

- software familiarization

- economic barriers

○ technical problems

- computer phobia

- language problems: most of them are only in English and this can be a barrier for many EFL students

○ quality of language: sometimes the language used is not always as accurate as desired

o content: the content is not appropriate for the level of our students or does not apply totally to the contents we are covering in our didactic unit

The use of the Internet in schools implies that both faculty (teachers) and educative centres (the schools and classrooms) must experience several changes. On the one hand, teachers need to keep updated and know the existence of these resources and their possibilities, and must know how to select the most appropriate ones for each situation. They also need continuous training in digital didactics to know the possibilities of the new electronic devices and services in the internet.

On the other hand, schools and classrooms need to be adapted by installing digital blackboard in class, creating new spaces like computer labs (for group work), or implementing a school intranet. Another important aspect we are to bear in mind when we are analysing different software is the criteria to select ICT resources. We need to evaluate carefully three aspects: the purpose, the design and the content of the program.

- Purpose:

- Students use critical thinking, reasoning and problem-solving skills.

- Provide feedback both to pupils and teachers.

- Design:

- Layout, colour and use of animation should be attractive.

- User-friendly and easy to use.

- Content: 
- Appropriate and relevant to students' interest as well as the curriculum.

○ Activities need be appropriate for students' level.

When we evaluate the different resources that we can find on the internet, the criteria to select them are slightly different. This time we need to analyse aspects like the content, the design, and the navigation.

- Content:

- Who wrote the pages? Are they experts?

What's the purpose of the pages?

Where does the content come from?

Why is the content useful for my purpose?

Design:

Are there useful headings and sub-headings?

Are the resources logically organized?

Is multimedia appropriately used?

Do the graphics impair the loading of the page?

Navigation:

- Do all the links work?

- Does it link back to the home page from other pages?

Hereby we can now make a list of some of the most useful resources for its exploitation in the FL classroom for specific purposes:

- Google Docs: A perfect tool to create and share documents. (http://www.youtube.com/watch)

- Issuu: To upload and view digital material. You can create your own library! (http://issuu.com)

- Picasa: An image organizer and an image viewer. (http://picasa.google.com/)

- Facebook - groups: To share files, pictures, create events, chat... (http://www.facebook.com)

- Slideshare: To share presentations and documents. (http://www.slideshare.net)

- Blogger: Free web for creating blogs. (https://www.blogger.com/start)

- Youtube: A video sharing website. (http://www.youtube.com)

- Skype: A software that enables different types of conversations. (http://www.skype.com)

- JClic: Applications to create educational activities. (http://clic.xtec.cat/es/index.htm)

- Delicious: A social bookmarking for sharing and storing. (http://delicious.com)

- CMapTools: A program to create concept maps. (http://cmap.ihmc.us/download/)

- Digital Blackboard: An interesting resource for teachers, that offers many more opportunities than the traditional blackboard. (http://dewey.uab.es/pmarques/pizarra.htm)

- Multimedia stories: A combination of text, clips, audio, photographs... so that stories become even more (http://ordenadoresenelaula.blogspot.com//comogestionar-un-proyecto-.htm)

- Multimedia PowerPoint: Power point is another way of creating interactive multimedia presentations. (http://www.artic.ua.es/sites/u38/sitio401/)

- Webquest: According to Bernie Dodge at San Diego State University, it is "an inquiry-oriented activity in which some or all of the information that learners interact with comes from resources on the Internet." (http://www.dgde.ua.es/wb/webquest/)

- Hot Potatoes: Another system to create educational activities. (http://hotpot.uvic.ca)

- ComicLife: A computer program that provides you with different templates so that you can create your own comics, picture albums, etc. (http://comiclife.com/)

\section{THE FUTURE OF TECHNICAL ENGLISH}

Internet has become a new platform for users because it has become easy for anyone to create, upload and share information with Web 2.0 technologies and we are more connected than ever. It's an umbrella term for developing social software applications such as social bookmarking, pod casting etc. which facilitates creativity, collaboration and sharing between users. Web 2.0 is read and write web. It's real time and live connection between users and a good revolution of Web 1.0. It enhances creativity, communication and collaboration; the words we use in education. We all use Facebook, YouTube, Google or blogs that let us create community. They are all Web 2.0 tools that we are familiar with.

As teachers, we are about to have the biggest discussion on education: How do we learn? Some of us have already explored the potential of social networking, media-sharing and other Web 2.0 tools though they are not designed especially for learning; and it's getting more popular everyday among our students. They have been using Web 2.0 for a long time. They write on blogs, upload photos and videos, build personal profiles and interact with each other every day. They all have their Myspace and Facebook accounts and this makes it easier for us to use this technology at schools because our students are already familiar through their own experiences and they are already motivated to use them. Here are some reasons why to use Web 2.0 in our classes:

- It increases the creativity. Any student can write, film, and publish a video or an audio. YouTube and Google video are used by our students everyday.

- It's collaborative. We can easily create social networks and communities of interests. I believe Wikipedia and Ning are the best examples for this and they are all free. 
- It promotes student centred learning. It allows users to become the producers of the knowledge. It enables us to share our work with other audience. For example, E-pals project is considered to be the world's largest online classroom.

- It provides many opportunities for language practice. Students can play with language and the context and it is more informal.

- It engages students. In fact, technology is always engaging. When we use these tools in classes, it doesn't seem like a required assignment for students. It also helps us to motivate our shy students to participate more in our lessons and the willingness to create and share is a great opportunity to learn and participate.

- It creates freedom and independence in learning which we can't find in our traditional education systems. Internet is available $24 / 7$ and this encourages our students to share information to a greater extent which is not available in our classes.

- It also reminds us that learning is not only limited to school boundaries.

- We can find more authentic audience. When students do paper work, teachers or other students can see it but when it is online, many other people can read, comment and contribute so Web 2.0 improves communication skills because students have a wider audience.

As teachers we need to find our own ways to use these technologies in our classes and consider the security issues and the copyright. We believe new technologies will come up but teachers will always be in the centre of education because our students will need our guidance more than ever. Teachers will be the ones who encourage and motivate the students to become better learners.

\section{CONCLUSIONS}

The expansion of ICT in all areas and strata of our society has occurred at great speed, and it is a continuous process as new technological elements are constantly appearing. The progressive decrease in costs of most technological products, as a result of the increase in production volumes and the optimization of manufacturing processes, is felt in prices and allows us to have more benefits for the same money, facilitating the introduction of these powerful technologies in all human activities and in all socio-economic fields

All these new technological appliances are not, so to say, the cure-all for all the educative situations in which to develop the daily practice and the educative intervention. Nonetheless, they open enduring paths to new ways of intervention prior to anything previously done or tried before. The use of ICTs is a new concept born as a countermeasure to the traditional web format, or even to the common and traditional uses of the Internet. Henceforth, it is important to notice hereby that it is a concept rather than a product.

From a wide perspective, the main contributions of ICTs to the Technical English field are gathered together in the following seven points:

1. Individual outcome of contents. That refers to the growing amount of content generated by the individual user. It promotes the role of teacher and students as active creators.

2. Benefit of the community effect. We can learn from and with other users, sharing our knowledge.

3. Benefit from the huge participation of the services offered with the ICTs.

4. Use of easy and intuitive tools without any technical requirements.

5. Use of open contents and free software. It implies a mixture of data and free spirit of innovation.

6. Creation of learning communities characterized by a common topic or issue.

7. Web effect. It moves from the individual study to the co-operation between peers.

\section{REFERENCES}

[1] Lys, F. (1999). "It's the pedagogy, not the technology, we have to worry about: Developing new tasks for a changing language curriculum", Fremdsprache lehren und lernen, FLuL (25). [2] Sáez Vacas, F. (1995). "La cadena multimedia". Cuadernos Pcweek, Multimedia, 11, 1-7.

[3] Fletcher-Flynn, C. M., \& Gravatt, B. (1995). "The efficacy of computer-assisted instruction (CAI): A meta-analysis". Journal of Educational Computing Research, 12, 219-241.

[4] Marzano, R.J. (1998). A Theory-Based MetaAnalysis of Research on Instruction. Aurora, Colorado: McREL.

[5] Weaver, G.C. (2000). "An Examination of the National Educational Longitudinal Study Database To Probe the Correlation between Computer Use in School and Improvement in Test Scores". Journal of Science Education and Technology, Volume 9, Number 2.

[6] Higgins, S. \& Moseley, D. (1999). “Teachers' Thinking about Information and Communications Technology and Learning: beliefs and outcomes". Teacher Development, Volume 5, Number 2. 